\title{
Electronic Markets on platform complexity
}

\author{
Rainer Alt ${ }^{1}$ (D) \\ Published online: 15 December 2021 \\ (c) The Author(s) 2021
}

Since the beginning of last year, the pandemic has been a dominant topic for societies worldwide. Stronger than in all prior decades since the rise of the information age, it brought to light the situation in the healthcare sector. It revealed that even in highly developed countries fundamental inefficiencies in information sharing as well as in coordination among the many actors involved in this industry existed. An interview with Germany's federal minister of health illustrates this by asserting that "faxes are still the most used way of communication in our health system, at least when it comes to communicating between the different players [...] Within a hospital, that might be very much digitised, but as soon as you want to communicate with another hospital or another player in the healthcare system, it's very much like the 1990s and not like 2020." (Evenstad, 2020). However, even in the 1990s approaches to address these inefficiencies were available. In fact, the necessary technologies and application concepts already emerged since the 1970s and solutions for electronic healthcare were also published in the first issues of Electronic Markets that date back to the mid-1990s. Among the topics were the improved flow and sharing of information among the multiple actors (Klein, 1995; Klein et al., 1996) and over the years a variety of general research articles addressed topics such as the adoption of mobile services (Akter et al., 2010; Cocosila \& Archer, 2010), secure information infrastructures (Dehling \& Sunyaev, 2014), open innovation (Daiberl et al., 2019) and smart services (Wiegard \& Breitner, 2019; Fischer et al. 2020). In 2013, a dedicated special issue on mobile health was published with five research papers and the guest editors have asserted that "healthcare delivery is a pervasive global challenge with huge ramifications for costs and human wellbeing. No nation is ready (or able) to deal with the multitude of confronting issues." (Vogel et al., 2013, p. 3).

\footnotetext{
Rainer Alt

rainer.alt@uni-leipzig.de

$1 \quad$ Leipzig University, Leipzig, Germany
}

\section{Ambivalence with healthcare platforms}

Eight years later, a second special issue on "digital healthcare services" now sees progress with many convincing projects on the one hand and a lack of widespread adoption on the other. The guest editors mention that "although the benefits of digital health services such as better accessibility of care are widely recognized, there has been no large-scale integration into regular healthcare delivery. Rather, there is an abundance of successful pilot projects, which fail to be introduced into the regular healthcare delivery systems." (Maier et al., 2021). It points at an ambivalence that characterizes the current situation:

- Complexity. On the one hand, even leading software companies were unsuccessful in rolling out and scaling their solutions. For example, Google discontinued its Google Health service in 2012 (Brown \& Weihl, 2011), Microsoft its HealthVault in 2019 (Pidun et al., 2021) and IBM its Watson Health offering in spring 2021 (Lohr, 2021). This suggests that in view of the technological resources of these major actors, the inhibiting factors might not have been primarily technological in nature. Among the specifics that are often attributed to the healthcare sector are its fragmented landscape of largely independent actors (e.g. physicians, hospitals, health insurances), the social nature of the relationship between patient and physician, the high levels of privacy concerns and the protection of personal data as well as the strong regulation and a resistance towards change in many countries. The complexity is emphasized by Sahni et al., (2021, p. 1677) who report for the US that the "administrative complexity of health care is profound. There are multiple transaction nodes, including more than 6000 hospitals, 11000 nonemployed physician groups [...], and 900 private payers; regulatory complexity $[\ldots]$ and contrasting incentives, for example, market-driven checks and balances, such as prior authorization." Obviously, the 
required solutions for mastering this complexity have either not appeared or have not seen adoption.

- Potentials. On the other hand, creating digital platforms and ecosystems in healthcare promises significant potentials, in particular, improvements in the quality and the cost of health-related services. The analysis of Sahni et al., (2021, p. 1677) continues that “an estimated $\$ 265$ billion, or approximately $28 \%$ of annual administrative spending, could be saved without compromising quality or access by implementing about 30 interventions that could be carried out in the next 3 years." Another recent study estimated that "the efficiency potential currently lost in the fragmented interplay of stakeholders, sectoral boundaries, and limited care coordination [...] account for up to $25 \%$ of health care spending in Europe and the US" (Pidun et al., 2021, p. 1). The same source argues that "now is the time for ecosystems in healthcare" with patients demanding more comprehensive and more convenient services, the adoption of technologies that enable ecosystem infrastructures and applications, as well as advances in regulation for electronic health records or telemedicine solutions. Thus, it is not surprising that competition is accelerating with incumbents like Roche or Karl Storz (see interview in this issue), and, in particular, with new entrants like Walmart, start-up companies such as Omada Health and (again) big tech companies with Amazon Care, Microsoft Azure for healthcare or Apple health app (Doniger 2021).

From the field of enterprise systems, the concept of a centralized topology has become a successful approach to address the organizational and technological complexity that is present within most enterprises, in particular, with growing firm size. It includes a single database that is used across functional departments and allows the design of cross-functional activity chains, i.e. business processes (Davenport, 1998). The same logic applies in the interorganizational setting. From a topological perspective the advantages are convincing: while a decentralized point-to-point topology features $n *(n-1)$ connections, the centralized hub-and-spoke topology shows only n connections. Driven by this reduced topological complexity, centralized platforms also spread among organizations in many industries with clearing centers, electronic markets or supply chain monitoring systems. This was in particular the case when numerous smaller distributed and independent actors were involved like in the healthcare domain. However, it is important to consider that within organizations the integration on the technological and the organizational level concurs with the institutional level, i.e. a single system and unified process design within a single firm. This is different between organizations and centralized solutions have repeatedly encountered resistance from incumbents or other actors - a situation that seems similar to the ambivalence in healthcare mentioned above.

\section{Complexity and digital platforms}

One possible explanation follows the co-evolution hypothesis that assumes an isomorphism between the organizational and the technological infrastructure (Alt, 2018; Riasanow et al., 2020). Although it recognizes the advantages of centralized platforms in reducing the topological complexity, it also sees them as solutions along a possible evolution path towards more decentralized solutions. It supports the observation in healthcare that a single centralized platform will be unable to sufficiently address the heterogeneous requirements in this industry. For example, the interview included in the present issue emphasizes that big tech platforms yield access to users (or patients) and superior analytic skills, but that they lack the medical domain knowledge and the data of healthcare institutions (Alt \& Zimmermann, 2021). Another research describes the evolution and interplay of multiple digital platforms in healthcare (Hermes et al., 2020b) and substantiates this with specific examples. It mentions established digital platforms for video conferencing and engagement, for searching, contacting and reviewing physicians, for matching users and fitness trainers, as well as the possible appearance of innovation platforms. Platforms for analytical and voice service, for transactions between medical institutions or for connecting IoT devices in the medical (or wellness) environment could be added to this list and point towards an ecosystem of platforms (Alt, 2021, p. 237). Ultimately, this suggests that the "healthcare industry is moving from simple linear value chains to two-sided markets mediated by central marketplaces, and then to complex interacting multi-sided markets mediated by platforms with super-modular/super-additive value creation." (Hermes et al. 2020b, p. 1052). A broad literature review by Paparova and Aanestad (2020) confirms that linking diverse (eHealth) platforms via boundary resources such as standardized APIs is an immediate need. In addition, several contributions have shown how these arrangements of multiple (per se still centralized) platforms might converge with developments, such as decentralized blockchain/ ledger infrastructures as well as emerging standards such as Health Level 7 (HL7) and electronic healthcare records, and cause greater interoperability among autonomous distributed actors (e.g. Al Omar et al., 2019; Dasaklis et al., 2018; Hoess et al., 2021).

Following the co-evolution assumption and the observations in the healthcare sector, the picture of digital 
platforms will also become more complex. Such aspects led to the notion of platform complexity, which was introduced to "define the range of possible activities on the platform and the related aspects of control" (Tilson et al., 2013 , p. 4625). Referring to the concept of generativity, the authors conceive platforms as open modular and adaptable systems that are sufficiently underspecified to allow multiple use cases. Using the example of the music industry, the research of Tilson et al. recognizes the interconnectedness of digital platforms on a vertical scale in seven levels from a physical towards an application layer. The authors argue that the generative and the intangible nature of digital platforms entails more interconnections among such platforms as well as a larger number of emerging platforms (Tilson et al., 2013, p. 4633). To understand the structure and behavior of complex multi-level and multi-directional causal systems, a dedicated complexity theory has evolved and was suggested as a valuable perspective in information systems research (Benbya et al., 2020). Based on this generic theoretical framework, complexity criteria (or drivers) were developed to substantiate the rather abstract determinants of complexity. For example, Sachse (2018, p. 24f) distinguished between structural complexity measures like the number of a system's elements, their diversity and the relationships between the elements as well as dynamic measures such as variation, self-organization dynamism and liveliness, adaptation to the environment and nonlinearity.

Figure 1 shows a simplified figure of a single digital ecosystem on the left that comprises the structural elements of the digital platform, i.e. the consumers and partners as well as the complementary products and services (adapted from Hyrynsalmi, 2014, p. 44). From a dynamic perspective it includes feedback loops that generate network effects and impetus for the ecosystem's continuous evolution. Linking the platform with another platform creates a multi-platform setting. On an aggregated (meta) level this leads to an ecosystem of platforms and ecosystems, which generates additional structures and dynamics. In analogy to large diversified corporations, recent research has coined the notion of platform conglomerates that are based on platform envelopment for this interplay of platforms as well as ecosystems. Contrary to conglomerates, which became dominant in the last century (e.g. General Electric), they are less based on vertical integration and enact control across organizations via their platforms. Although this new perspective arouses many research questions (see Hermes et al., 2020a), the complexity measures indicate some characteristics (see right matrix in Fig. 1).

- Structural complexity includes the elements and linkages, which comprise the number of interconnected platforms and ecosystems together with the number of external APIs and their connections to other APIs (Chen et al. 2021; Um and Yoo 2016). The latter determine the degree of multihoming, i.e. APIs that are compatible with multiple ecosystems.

- Dynamic complexity captures the effects of generativity in fostering innovation and change within the meta ecosystem. The dynamics will often be nonlinear and self-organizing in nature and lead to new market segments, generic roles and value streams as well as blurring industry boundaries (Hermes et al., 2020b; Um \& Yoo, 2016).

Thus, instead of a single big tech company dominating healthcare, it may be expected that platforms of medical providers and research institutions become more interoperable with consumer platforms and that industry as well as platform standards will be key. They might allow for anonymity

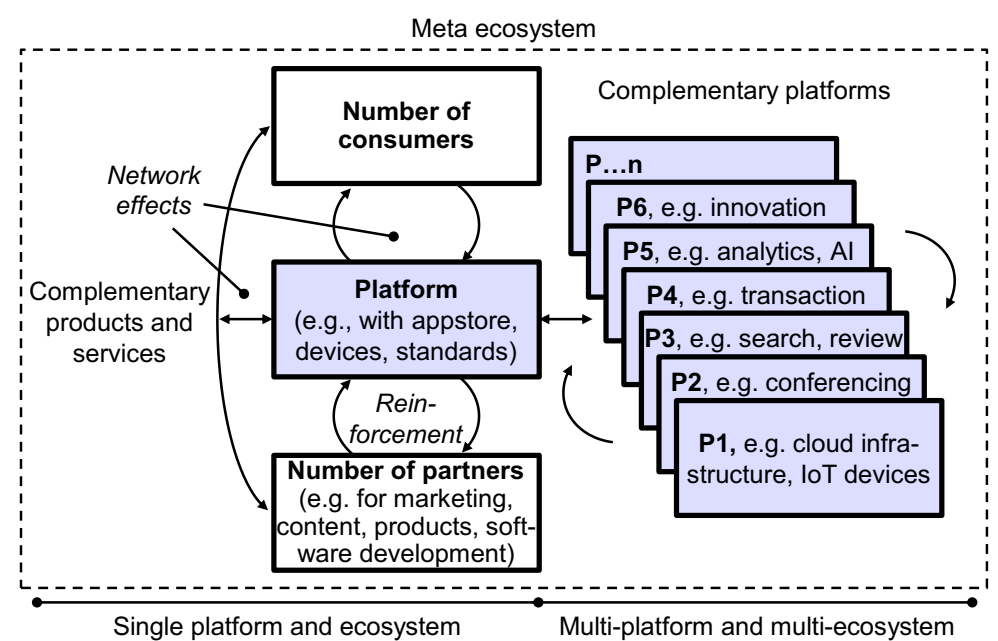

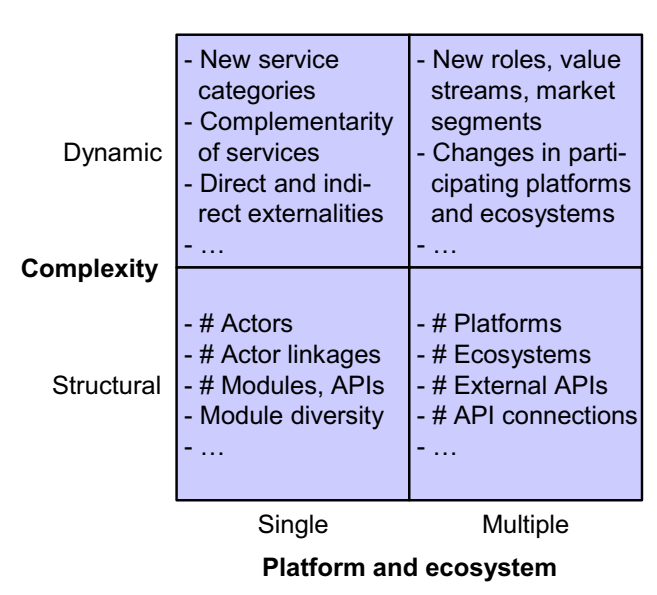

Legend: Al: Artificial intelligence, P: platform, \#: number

Fig. 1 Dimensions of platform complexity 
as well as openness and yield opportunities for competing or complementing firms of all sizes. As suggested by Cozzolino et al. (2021), the evolution of such ecosystems could provoke a state of coopetition among the actors involved. The emerging picture might be similar to the financial industry, where platform complexity has been described as a result of platform incompleteness and component replacement (Dhar and Stein 2017). If platform providers aim to remain competitive, they need to consider replacing existing or adding new functionalities with external components. For example, a digital exchange might consider to replace centralized clearing functionalities with external services based on blockchain technology. Standardized interfaces will be an important enabler to contain the subsequent rising platform complexity and point to another upcoming issue of Electronic Markets titled "Standardization for platform ecosystems" (van de Kaa et al. 2020).

\section{Articles of present issue}

In the present issue, half of the overall 14 papers belong to the special issue that provides research results in the exciting domain of digital healthcare services. These articles are introduced in the separate preface by the guest editors Edith Maier, Ulrich Reimer and Nilmini Wickramasinghe (Maier et al., 2021). Closely related to the special issue theme are two additional papers. The first is an interview with Werner Dorfmeister, who has been responsible for global sales at Karl Storz, a manufacturer of medical instruments, and is currently a Vice President at Das:Lab, a service provider for digital lab testing in Germany. As mentioned above, he attributes digitalization a high potential to improve the distributed healthcare industry with many isolated legacy systems, despite the strong regulation of this sector in many countries. He identifies the three main digitalization areas, i.e., telemedicine, hospital and patient management as well as a sector-wide digital infrastructure. Digital platforms are described as key enablers to address current inefficiencies and to leverage future potentials towards improved care and treatments as well as patient-orientation, such as digital patient pathways. In particular, he recognizes the competition between big digital platform companies who have access to patient data and large medial companies with their pools of medical data (Alt \& Zimmermann, 2021).

The second article that relates to the special issue section is a general research paper that presents a comprehensive literature review and a research agenda in the area of health information systems. Titled "Keeping pace with the healthcare transformation", the authors Nadine Ostern, Guido Perscheid, Caroline Reelitz and Jürgen Moormann have analyzed almost 500 research papers along five phases and identify three areas of improvement for health information systems. These refer to understanding the future behavior of actors and the causalities in sustainable and inclusive healthcare ecosystems. In view of platform complexity, the authors also expect "multi-layered ecosystems that encourage joint business strategies" to emerge and radical innovation "by putting the patient at the core of all innovation efforts." (Ostern et al., 2021).

Although not directly related to the healthcare domain, another general research paper, links to platform complexity from the perspective of cloud computing ecosystems. Titled "Cloud computing ecosystem model: evaluation and role clusters", the authors Sebastian Floerecke, Franz Lehner and Sebastian Schweikl present a comprehensive and structured view on an ecosystem. Based on an analysis of 758 organizations they identify five role categories, which they visualized with interdependencies in their "Passau Cloud Computing Ecosystem Model". In addition to the role categories, the authors empirically derived five role clusters that bundle multiple roles and shed light on the competitive landscape of this broad ecosystem. Among them are actors offering advisory services, the big tech cloud players, telecommunications companies, application software providers as well as service providers for certification and training (Floerecke et al., 2021).

The last three general research papers address topics in the larger field of e-commerce. First, Urvashi Tandon, Amit Mittal and Sridhar Manohar examine "the impact of intangible product features and e-commerce institutional mechanics on consumer trust and repurchase intention" based on a survey among e-commerce users in India. They reveal that return and free shipping policies as well as virtual try-on and pay-on-delivery features positively affect trust, which bears the potential to increase conversion rates and the likelihood of repeated purchases. Remarkably, these policies and features were more important for shoppers than the availability of vendor guarantees and warranties (Tandon et al., 2021).

Another general research paper in the e-commerce context sheds light on the role of social media for customer engagement. Titled "Customer engagement and performance in social media: a managerial perspective", the authors Othman Boujena, Isabelle Ulrich, Aikaterini Manthiou and Bruno Godey present the results of a broad cross-industry set of interviews, which includes large international companies as well as some SMEs. They show the metrics that were used to analyze customer engagement on the main social media platforms and the challenges that practitioners encountered as well as improvements that take into account more complex customer journeys (Boujena et al., 2021).

The third paper emphasizes the market for personal data. Following a special issue on personal data markets published in 2015 (Spiekermann et al., 2015), the research of David Agogo presents a recent analysis of the structure of this market as well as on the behavior of the major actors. The 
author confirms the growing volume of personal data and reports that despite regulations such as GDPR have emerged, this data is often shared with third parties on a market that is little visible. In particular, his social network analysis reveals that the websites from actors in different industries are strongly interrelated and that users typically lack insights for what purposes their data is actually being used (Agogo, 2021).

Finally, a big thank you goes to all guest editors, associate editors, authors and reviewers, who dedicated much effort in making this issue of Electronic Markets possible. Much gratitude also goes to three long-term members of Electronic Markets' editorial board, who have now decided to step down. Thank you Martin Spann from Munich University, Xiaona Zheng from Peking University, and Jing Zhao from China University of Geosciences in Wuhan for your service!

Funding Open Access funding enabled and organized by Projekt DEAL.

Open Access This article is licensed under a Creative Commons Attribution 4.0 International License, which permits use, sharing, adaptation, distribution and reproduction in any medium or format, as long as you give appropriate credit to the original author(s) and the source, provide a link to the Creative Commons licence, and indicate if changes were made. The images or other third party material in this article are included in the article's Creative Commons licence, unless indicated otherwise in a credit line to the material. If material is not included in the article's Creative Commons licence and your intended use is not permitted by statutory regulation or exceeds the permitted use, you will need to obtain permission directly from the copyright holder. To view a copy of this licence, visit http://creativecommons.org/licenses/by/4.0/.

\section{References}

Agogo, D. (2021). Invisible market for online personal data: An examination. Electronic Markets, 31(4). https://doi.org/10.1007/ s12525-020-00437-0.

Akter, S., D'Ambra, J., \& Ray, P. (2010). Service quality of mHealth platforms: Development and validation of a hierarchical model using PLS. Electronic Markets, 20(3-4), 209-227. https://doi.org/ 10.1007/s12525-010-0043-x.

Al Omar, A., Bhuiyan, M. Z. A., Basu, A., Kiyomoto, S., \& Rahman, M. S. (2019). Privacy-friendly platform for healthcare data in cloud based on blockchain environment. Future Generation Computer Systems, 95, 511-521. https://doi.org/10.1016/j. future.2018.12.044.

Alt, R. (2018). Electronic Markets and current general research. Electronic Markets, 28(2), 123-128. https://doi.org/10.1007/ s12525-018-0299-0.

Alt, R. (2021). Electronic Markets on digital platforms and AI. Electronic Markets, 31(2), 233-241. https://doi.org/10.1007/ s12525-021-00489-w.

Alt, R., \& Zimmermann, H.-D. (2021). The digital transformation of healthcare - An interview with Werner Dorfmeister. Electronic Markets, 31(4). https://doi.org/10.1007/s12525-021-00476-1.
Benbya, H., Nan, N., Tanriverdi, H., \& Yoo, Y. (2020). Complexity and information systems research in the emerging digital world. MIS Quarterly, 44(1), 1-18. https://doi.org/10.25300/ MISQ/2020/13304.

Boujena, O., Ulrich, I., Manthiou, A., \& Godey, B. (2021). Customer engagement and performance in social media: a managerial perspective. Electronic Markets, 31(4). https://doi.org/10. 1007/s12525-020-00450-3.

Brown, A., \& Weihl, B. (2011). An update on Google Health and Google PowerMeter. Google Official Blog, June 24. https:// googleblog.blogspot.com/2011/06/update-on-google-healthand-google.html, accessed 07.11.21.

Chen, L., Yi, J., Li, S., \& Tong, T. W. (2021). Platform governance design in platform ecosystems: Implications for complementors' multihoming decision. Journal of Management. https://doi.org/ $10.1177 / 0149206320988337$.

Cocosila, M., \& Archer, N. (2010). Adoption of mobile ICT for health promotion: An empirical investigation. Electronic Markets, 20(3-4), 241-250. https://doi.org/10.1007/ s12525-010-0042-y.

Cozzolino, A., Corbo, L., \& Aversa, P. (2021). Digital platform-based ecosystems: The evolution of collaboration and competition between incumbent producers and entrant platforms. Journal of Business Research, 126, 385-400. https://doi.org/10.1016/j.jbusr es.2020.12.058.

Daiberl, C. F., Oks, S. J., Roth, A., Möslein, K. M., \& Alter, S. (2019). Design principles for establishing a multi-sided open innovation platform: Lessons learned from an action research study in the medical technology industry. Electronic Markets, 29(4), 711-728. https://doi.org/10.1007/s12525-018-0325-2.

Dasaklis, T.K., Casino, F., \& Patsakis, C. (2018). Blockchain meets smart health: Towards next generation healthcare services. Proceedings 9th International Conference on Information, Intelligence, Systems and Applications (IISA). https://doi.org/10.1109/ IISA.2018.8633601.

Davenport, T. H. (1998). Putting the enterprise into the enterprise system. Harvard Business Review, 76(4), 121-131.

Dehling, T., \& Sunyaev, A. (2014). Secure provision of patientcentered health information technology services in public networks - leveraging security and privacy features provided by the German nationwide health information technology infrastructure. Electronic Markets, 24(2), 89-99. https://doi.org/10.1007/ s12525-013-0150-6.

Dhar, V., \& Stein, R.M.(2017). FinTech platforms and strategy. Commun. ACM, 60(10),32-35. https://doi.org/10.1145/313272.

Evenstad, L. (2020). Coronavirus has changed perception of healthtech, say ministers. Computerweekly, Sep. 29, 2020. https://www. computerweekly.com/news/252489793/Coronavirus-has-changedperception-of-healthtech-say-ministers, accessed 07.11.21.

Fischer, M., Heim, D., Hofmann, A., Janiesch, C., Klima, C., \& Winkelmann, A. (2020). A taxonomy and archetypes of smart services for smart living. Electron Mark, 30(1), 131-149. https://doi.org/ 10.1007/s12525-019-00384-5.

Floerecke, S., Lehner, F., \& Schweikl, S. (2021). Cloud computing ecosystem model: evaluation and role clusters. Electronic Markets, 31(4). https://doi.org/10.1007/s12525-020-00419-2.

Fürstenau, D., Auschra, C., Klein, S., \& Gersch, M. (2019). A process perspective on platform design and management: Evidence from a digital platform in health care. Electronic Markets, 29(4), 581-596. https://doi.org/10.1007/s12525-018-0323-4.

Hermes, S., Kaufmann-Ludwig, J., Schreieck, M., Weking, J., \& Böhm, M. (2020a). A taxonomy of platform envelopment: Revealing patterns and particularities. Proceedings Americas Conference on Information Systems (AMCIS). Salt Lake City. https://aisel.aisnet. org/amcis2020/strategic_uses_it/strategic_uses_it/17. 
Hermes, S., Riasanow, T., Clemons, E. K., Böhm, M., \& Krcmar, H. (2020b). The digital transformation of the healthcare industry: Exploring the rise of emerging platform ecosystems and their influence on the role of patients. Business Research, 13(3), 10331069. https://doi.org/10.1007/s40685-020-00125-x.

Hoess, A., Schlatt, V., Rieger, A., \& Fridgen, G. (2021). The blockchain effect: From inter-ecosystem to intra-ecosystem competition. Proceedings $29^{\text {th }}$ European Conference on Information Systems. https://aisel.aisnet.org/ecis2021_rp/36.

Hyrynsalmi, S. (2014). Letters from the war of ecosystems - An analysis of independent software vendors in mobile application marketplaces. PhD Thesis, University of Turku. https://doi.org/10. 13140/2.1.4076.4484.

Klein, S. (1995). INTHES - EDI integration in the health sector. Electronic Markets, 5(3), 20.

Klein, S., Lee, R. M., Lei, L., \& Qureshi, S. (1996). Pharmatica: Supporting the complex pharmaceutical information needs in the changing healthcare sector. Electronic Markets, 6(2), 25-26.

Lohr, S. (2021). What ever happened to IBM's Watson? The New York Times, July 16. https://www.nytimes.com/2021/07/16/technology/ what-happened-ibm-watson.html, accessed 07.11.21.

Maier, E., Reimer, U., \& Wickramasinghe, N. (2021). Digital healthcare services. Electronic Markets, 31(4). https://doi.org/10.1007/ s12525-021-00513-z.

Ostern, N., Perscheid, G., Reelitz, C., \& Moormann, J. (2021). Keeping pace with the healthcare transformation: a literature review and research agenda for a new decade of health information systems research. Electronic Markets, 31(4). https://doi.org/10.1007/ s12525-021-00484-1.

Paparova, D., \& Aanestad, M. (2020). Governing innovation in e-health platform ecosystems - key concepts and future directions. Selected Papers of the IRIS, Issue Nr. 11, 4. https://aisel. aisnet.org/iris2020/4.

Pidun, U., Knust, N., Kawohl, J., Avramakis, E., \& Klar, A. (2021). The untapped potential of ecosystems in health care. Boston Consulting Group.

Riasanow, T., Flötgen, R.J., Greineder, M., Möslein, D., Böhm, M., \& Krcmar, H. (2020). Co-evolution in business ecosystems: Findings from literature. In Mayr, H.C., Rinderle-Ma, S., \& Strecker, S. (Eds.). 40 years EMISA, Lecture Notes in Informatics, Bonn, pp. $77-90$.
Sachse, S. (2018). Customer-centric service management. $\mathrm{PhD}$ thesis, Leipzig University. https://nbn-resolving.org/urn:nbn:de:bsz:15qucosa2-320862.

Sahni, N. R., Carrus, B., \& Cutler, D. M. (2021). Administrative simplification and the potential for saving a quarter trillion dollars in health care. JAMA, 326(17), 1677-1678. https://doi.org/10.1001/ jama.2021.17315.

Spiekermann, S., Böhme, R., Acquisti, A., \& Hui, K. L. (2015). Personal data markets. Electronic Markets, 25(2), 91-93. https://doi. org/10.1007/s12525-015-0190-1.

Tandon, U., Mittal, A., \& Manohar, S. (2021). Examining the impact of intangible product features and e-commerce institutional mechanics on consumer trust and repurchase intention. Electronic Markets, 31(4). https://doi.org/10.1007/s12525-020-00436-1.

Tilson, D., Sørensen, C., \& Lyytinen, K. (2013). Platform complexity: Lessons from the music industry. Proceedings $46^{\text {th }}$ Hawaii International Conference on System Sciences (HICSS). https://doi.org/ 10.1109/HICSS.2013.449.

Um, S., \& Yoo, Y. (2016). The co-evolution of digital ecosystems. Proceedings $37^{\text {th }}$ International Conference on Information Systems (ICIS), Dublin.

van de Kaa, G., Viardot,E., \& McCarthy, I.P. (2020). CfP special issue on "Standardization forplatform ecosystems". Electron Mark. http://www.electronicmarkets.org/call-for-papers/singleview-for-cfp/datum/2020/10/08/cfp-special-issue-on-standardiz ation-for-platforms-ecosystems/, accessed 10.11.2021.

Vogel, D., Viehland, D., Wickramasinghe, N., \& Mula, J. M. (2013). Mobile health. Electronic Markets, 23(1), 3-4. https://doi.org/10. 1007/s12525-013-0121-y.

Wiegard, R.-B., \& Breitner, M. H. (2019). Smart services in healthcare: A risk-benefit-analysis of pay-as-you-live services from customer perspective in Germany. Electronic Markets, 29(1), 107-123. https://doi.org/10.1007/s12525-017-0274-1.

Publisher's Note Springer Nature remains neutral with regard to jurisdictional claims in published maps and institutional affiliations. 